\title{
Fabrication and characterization of porous alumina with denser surface layer by direct foaming
}

\author{
National Institute of Advanced Industrial Science and Technology, \\ 2266-98 Anagahora, Shimo-Shidami, Moriyama-ku, Nagoya 463-8560, Japan
}

Akihiro SHIMAMURA ${ }^{\dagger}$, Manabu FUKUSHIMA, Mikinori HOTTA, Tatsuki OHJI and Naoki KONDO

\begin{abstract}
Porous alumina with a denser surface layer is fabricated from an alumina/novolac composite body containing hexamethylenetetramine (HMT) that is used as a blowing agent and a curing agent for the novolac resin. A gas blown from HMT leads to the formation of pores up to submillimeter inside the alumina/novolac composite body. On the other hand, the denser surface layer without large pores is formed by the gas released from the surface during blowing. The blowing condition for the alumina/ novolac composite body is examined as a function of heat-treatment temperature in order to investigate the formation of the pore and the surface layer. Porous alumina with the denser surface layer is obtained through de-binding and sintering of the body. This paper also describes the microstructure and mechanical strength of the sintered porous alumina, and advantages of the denser surface layer.
\end{abstract}

(C2017 The Ceramic Society of Japan. All rights reserved.

Key-words : Porous alumina, Surface structure, Direct-foaming, Novolac resin

[Received July 28, 2016; Accepted October 24, 2016]

\section{Introduction}

Porous ceramics have numerous industrial applications, including lightweight structural components, absorbents, filters, catalysts and thermal insulators, due to a variety of specific properties, such as their high surface area, lightweight, and low thermal conductivity. ${ }^{1)-4)}$ These specific properties depend on parameters such as pore size, pore morphology, pore interconnections and orientation. ${ }^{5)-7)}$ Generally speaking, the mechanical strength of porous ceramics decreases with increasing porosity. The processing method used for porous ceramics is one of the most important factors that influences their porosity. Tremendous efforts have therefore been devoted for the researches on the processing routes of porous ceramics, including partial sintering, sacrificial fugitives, replica templates, and direct foaming. . $), 9)^{9}$ Among these techniques, the direct foaming route allows low cost and easy production of highly porous ceramic materials.

In direct foaming techniques, a ceramic/binder (green) foam is fabricated via gas incorporation (physical or chemical blowing); the foam is then stabilized, debound, and sintered. ${ }^{10), 11)}$ The key aspects in this process are the stabilization and consolidation mechanisms. However, the ceramic/binder foam is a thermodynamically unstable system in which heat treatment (drying, debinding) and gas bubble coarsening can lead to foam degradation and final destruction.

We have previously proposed a new direct-foaming approach for porous reaction-bonded $\mathrm{SiC}(\mathrm{RB}-\mathrm{SiC})$ with a denser surface layer derived from the $\mathrm{Si}$ / novolac resin containing hexamethylenetetramine (referred to as "novolac-HMT"). ${ }^{12)}$ In this approach, the novolac resin (the carbon source for the RB-SiC) ${ }^{13), 14)}$ was used as the binder material, and HMT was used as the blowing/ curing agent for the novolac resin. The blowing gas from HMT produced uniformly dispersed spherical pores inside the com-

Corresponding author: A. Shimamura; E-mail: a-shimamura@aist. go.jp posite, which were then stabilized through a curing reaction between the blowing gas and the novolac resin. During the heat treatment, a filter paper was placed on the surface in order to release the blowing gas near the surface toward the outside, which resulted in the formation of a flat and denser surface layer. This denser surface layer improved the mechanical strength of the sintered specimens by approximately $30 \%$ compared to that of specimens without the denser surface layer. However, the mechanism behind the formation of porous structures with denser surface layers by the direct-foaming using the novolac-HMT was still unclear. This direct foaming process could potentially be applied to the fabrication of other porous ceramics that are sintered through solid phase sintering such as alumina-, zirconia-, magnesia- and silica-based ceramics. For these ceramics, the novolac-HMT has to be removed completely, which is different from the porous $\mathrm{RB}-\mathrm{SiC}$ in our previous work. Therefore, the porous structures prepared in this study should differ from that of porous $\mathrm{RB}-\mathrm{SiC}$.

In this study, we examine whether the direct foaming process described above can also be applied to the fabrication of porous alumina, and act as a model for typical conventional ceramic. Further, we carefully investigate the fabrication mechanism of the porous structure and the denser surface by changing the heating temperature to examine the blowing conditions. Disc-shaped alumina/novolac-HMT composites were prepared by press molding followed by heating. After blowing from HMT, the specimens were debound and sintered. Both the surface and bulk structures of the porous alumina were characterized by their porosity, pore size distribution and mechanical strength measurements as well as by microstructural observation.

\section{Experiments and characterization}

Coarse alumina (purity: $>99 \%, \mathrm{D}_{50}=11.9 \mu \mathrm{m}$; Fujimi Incorporated Co.Ltd., Aichi, Japan) and fine alumina powders (purity: 99.48\%, $\mathrm{D}_{50}=0.55 \mu \mathrm{m}$; Showa Denko Co.Ltd., Tokyo, Japan) were mixed in a mass ratio of 98:2 (coase:fine). We previously 


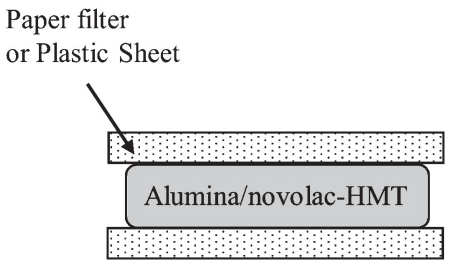

Fig. 1. Schematic illustration of the disc-shaped composite with filter papers during blowing.

reported that blowing was observed above a novolac-HMT content of $60 \mathrm{vol} \%$, while pore coarsening occurred at $80 \mathrm{vol} \%$. $\left.^{15}\right)$ The content of the novolac-HMT was thus fixed at $60 \mathrm{vol} \%$ in this study. The mixed alumina powder was blended with novolacHMT powder (SP1101 novolac type with $9 \mathrm{wt} . \%$ of curing agent: HMT, $\mathrm{D}_{50}=24.8 \mu \mathrm{m}$; Asahi Organic Chemicals Industry Co. Ltd., Tokyo, Japan) at a volume ratio of 40:60 (mixed alumina:novolac-HMT) for one hour under dry conditions by a V-type mixer. Using a steel mold, disc-shaped alumina/novolacHMT specimens with a diameter of approximately $45 \mathrm{~mm}$ and a thickness of approximately $3 \mathrm{~mm}$ were formed at $20 \mathrm{MPa}$. A schematic illustration of the disc-shaped composites undergoing the heat-treatment is shown in Fig. 1. Specimens were covered with a filter paper (pore size $2.7 \mu \mathrm{m}$ ) and heated for one hour at atmospheric conditions, and subsequently cooled down to room temperature. Specimens for heating at each temperature were prepared separately, and the heating rate was fixed at $2^{\circ} \mathrm{C} \mathrm{min}^{-1}$. The density of specimens after heating was calculated from its weight and volume. As a comparison, the disc-shaped composites were covered with dense plastic (polyethylene terephthalate) sheets instead of the filter papers were heated at $150^{\circ} \mathrm{C}$ for one hour. To prepare the final porous alumina after blowing, all specimens were debound under flowing $\mathrm{N}_{2}$ gas at $800^{\circ} \mathrm{C}$ for one hour and subsequently sintered at $1600^{\circ} \mathrm{C}$ for one hour in air.

Thermal behavior of the novolac-HMT binder was measured under air flow by differential scanning calorimeter/thermogravimetric analysis (DSC/TG, Q600, TA instruments, Delaware, USA). The macrostructure of the specimens before and after blowing was observed by an optical microscope (SMZ1500, Nikon Corp., Tokyo, Japan). The pore-size distribution of the porous alumina was measured using a mercury intrusion porosimeter (Autopore 9520, Shimadzu Co, Kyoto, Japan). Specimens were cut into a small piece (about $1 \mathrm{~g}$ ) and placed in a sample holder with $0.4 \mathrm{~mL}$ stem volume with mercury, after which the pressure was initially set at 0.5 psia and increased up to about $6.0 \times 10^{4}$ psia during measurement. Surface microstructures and cross morphologies of the porous alumina specimens were observed using a optical microscope and a scanning electron microscope (SEM, JSM-5600, JEOL Ltd., Tokyo, Japan). The Archimedes method using vacuum-assisted water infiltration was used to determine the apparent densities and porosities of the porous alumina specimens. The three-point bending strength was measured using a testing machine (MTS Systems Corporation, Sintech 10/GL, Minnesota, USA) with a span of $30 \mathrm{~mm}$, and a crosshead speed of $0.5 \mathrm{~mm} / \mathrm{min}$ at room temperature using rectangular-shaped specimens $(4.0 \mathrm{~mm} \times 3.0 \mathrm{~mm} \times 30 \mathrm{~mm})$.

\section{Results and discussion}

The thermal behavior of the novolac-HMT binder was studied by DSC/TG measurement. Figure 2 shows the DSC/TG curves of the novolac-HMT powder, where endothermic and exothermic peaks were observed at 82 and $156^{\circ} \mathrm{C}$, respectively. The endo-

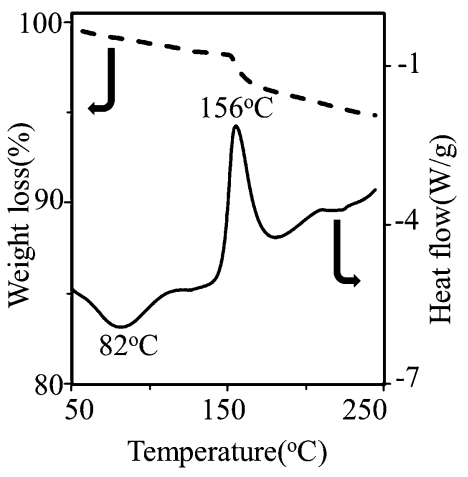

Fig. 2. DSC/TG curve of the novolac-HMT binder.

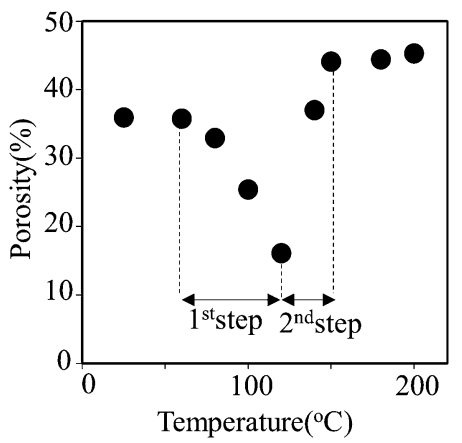

Fig. 3. Porosity of the composite (alumina/novolac-HMT) as a function of heat-treatment temperature.

thermic peak at $82^{\circ} \mathrm{C}$ was attributed to melting of the novolac resin, ${ }^{16)}$ while the exothermic peak at $156^{\circ} \mathrm{C}$ was to a typical curing reaction between the novolac resin and HMT. ${ }^{16)-19)}$ A steep weight loss was also observed along with the curing reaction. The curing mechanism of the novolac resin with HMT has been described using several methods, including ${ }^{13} \mathrm{C}$ and ${ }^{15} \mathrm{~N}$-Nuclear Magnetic Resonance, Fourier Transform-Infrared Spectroscopy and Thermogravimetric-Mass Spectrometry. ${ }^{16), 20), 21)}$ From those reports, it can be determined that up to temperatures of $150^{\circ} \mathrm{C}$, HMT decomposed to intermediates such as benzoxazine- and benzilamine-type molecules, which then reacted with the novolac molecules to bridge between them. Above $150^{\circ} \mathrm{C}$, these bridges transformed to methylene linkages between the novolac molecules, which resulted in the formation of three dimensional networks. During the curing reaction, decompositon products (mainly $\mathrm{NH}_{3}$ gas) were formed as a by-product of the curing reaction, ${ }^{21), 22)}$ a steep weight loss was observed in the TG curve of the novolac-HMT when the curing reaction occurred around $150^{\circ} \mathrm{C}$. Thus, the novolac-HMT binder showed two thermal events at $82^{\circ} \mathrm{C}$ for melting of the novolac resin and at $156^{\circ} \mathrm{C}$ for the curing reaction with the blowing gas from HMT.

Figure 3 shows the porosity of the specimens as a function of the heat-treatment temperature. After the heat-treatment, the porosity of each specimen was calculated from both theoretical and actual densities. Theoretical densities of the composites were calculated using the rule of mixtures and the density of $\mathrm{Al}_{2} \mathrm{O}_{3}$ $\left(4.0 \mathrm{~g} \cdot \mathrm{cm}^{-3}\right)$ and novolac resin $\left(1.2 \mathrm{~g} \cdot \mathrm{cm}^{-3}\right)$, while the actual densities were calculated from the weight and volume of a specimen. The initial porosity at $20^{\circ} \mathrm{C}$ was $36 \%$, which remained constant up to $60^{\circ} \mathrm{C}$. However, the porosity drastically changed during the heat-treatment between 60 and $150^{\circ} \mathrm{C}$. This porosity change can be depicted as a two step processes, as shown in 


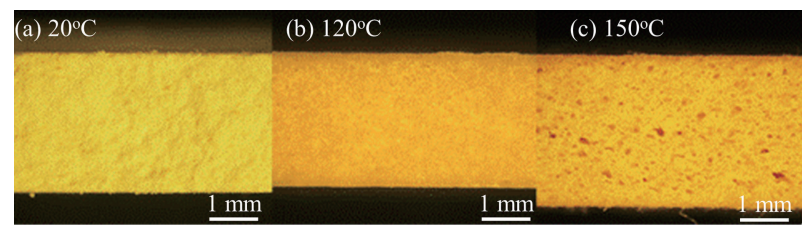

Fig. 4. Cross-sectional photo images of (a) the initial specimen at $20^{\circ} \mathrm{C}$, (b) at $120^{\circ} \mathrm{C}$ in the first step, and (c) at $150^{\circ} \mathrm{C}$ in the second step.

Fig. 3. In the first step, which was the melting of the novolacHMT, the porosity gradually decreased as the temperature increased from 80 to $120^{\circ} \mathrm{C}$. The porosity reached a minimum of $16 \%$ at $120^{\circ} \mathrm{C}$. At the same time, the volume of the specimen at $120^{\circ} \mathrm{C}$ decreased by $25 \mathrm{vol} . \%$, indicating that the decrease of the porosity caused by specimen shrinkage. In the second step, the porosity rapidly increased, reaching a maximum of $44 \%$ at $150^{\circ} \mathrm{C}$, at which point the novolac-HMT curing reaction occurred. The volume of the specimen at $150^{\circ} \mathrm{C}$ increased by 47 vol.\% compared to that at $120^{\circ} \mathrm{C}$ in the first step, indicating that the increase of the porosity was due to specimen expansion. Thus, the specimen shrunk due to the melting of the novolac resin first, and then expanded due to the blowing gas from the HMT.

Figure 4 shows cross-sectional images of the specimens: their initial state at $20^{\circ} \mathrm{C}$ [Fig. 4(a)], after the first step at $120^{\circ} \mathrm{C}$ [Fig. 4(b)], and after the second step at $150^{\circ} \mathrm{C}$ [Fig. 4(c)]. As shown in Fig. 4(a), no large defects could be observed in the starting specimen, which indicated that they were well formed by press molding. Figure 4(b) shows a cross-sectional structure that appears to be denser than the staring specimen due to shrinkage. As shown in Fig. 3, shrinkage of the composites started at $80^{\circ} \mathrm{C}$ and continued up to $120^{\circ} \mathrm{C}$. Jones ${ }^{23)}$ reported that the viscosity of the novolac resin without a curing agent decreases as the temperature increases due to breakdown of the association forces, mainly from hydrogen bonding. Thus, the driving force for the observed shrinkage was the change in free energy through a decrease in specimen surface area by melting of the novolac resin followed by rearrangement of the molten novolac resin with the alumina particles in the specimen. Although the specimen achieved a melting state between 80 and $120^{\circ} \mathrm{C}$, the viscosity was high enough to maintain a dispersion of alumina particles.

Figure 4(c) shows that spherical pores were formed by the blowing gas from HMT in the second step, leading to the expansion of the specimen. No millimeter-sized coarse pores were observed, which indicates that the spherical pores were welldispersed and stabilized before coalescence. This is due to the curing of the novolac resin in the formed pores by the blowing gas, which prevented pore coarsening. The optimized blowing temperature for obtaining the maximum porosity was concluded to be $150^{\circ} \mathrm{C}$. While spherical pores were observed on the inside, they were merely observed near the surface of the top and bottom of the specimen that were covered with the filter paper during the heat treatment. The blowing gas was evolved outward through the filter paper, which suppressed the formation of spherical pores near the surface. As a result, a porous structure with denser surface layers formed during the second step at $150^{\circ} \mathrm{C}$.

Thus, when a thermosetting resin (novolac resin in this case) is used in the direct-foaming process, the following points should be considered for fabrication of porous structures, as also pointed out by Fukushima et al. ${ }^{11)}$ (1) Firstly, blowing should occur before the thermosetting resin cures, as the viscosity of the melt would increase dramatically with the formation of a rigid structure, which would require a very high pressure for successful

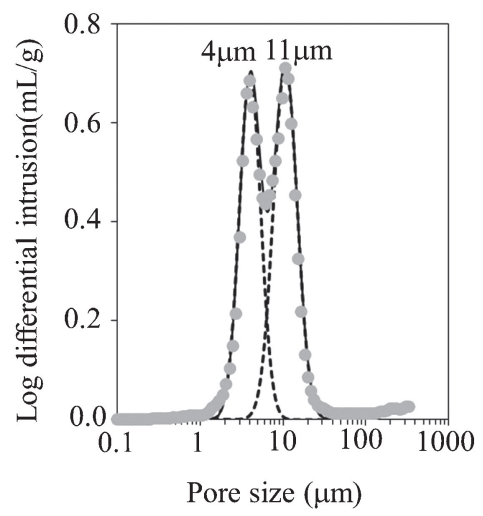

Fig. 5. Pore size distribution of the porous sintered alumina. Gray circles represent experimental data. Dot-line represents deconvoluted peaks.

foaming. (2) Secondly, the fluidity of the molten resin should be adequate to retain the gas produced from the blowing agent. If blowing occurs before the resin melts, foam formation cannot occur, as the blowing gas will escape outside. (3) Thirdly, the foamed body should be cured after blowing in order to retain the shape and morphology of the pores during the pyrolysis step.

The porosity of the porous alumina, as measured with mercury intrusion porosimetry, was $64.3 \%$, while the pore size distribution could be deconvoluted into two Gaussian components with peaks at 4 and $11 \mu \mathrm{m}$ (shown with dot-lines in Fig. 5). The peak area ratios of these peaks were 47.0 and $53.0 \%$, respectively. The distribution peak at $11 \mu \mathrm{m}$ was attributed to the spherical pores formed by blowing from HMT. The peak value actually indicates the window-like pores (the contact points between spherical pores) rather than the diameter of the spherical pore. Since liquid mercury was poured into the spherical pores through the bottle neck, mercury intrusion porosimetry could not distinguish the shape of a spherical pore so-called "ink-bottle-type pore" from a long cylinder-type pore. ${ }^{24)}$ On the other hand, the peak at $4 \mu \mathrm{m}$ corresponded to a single pore size distribution of the porous alumina prepared by press molding without novolac-HMT (not shown). This type of pore was not observed in the porous RB$\mathrm{SiC}$ of the previous study. Thus, the porous alumina specimens exhibit a bimodal distribution as a result of both the spherical pores from the blowing due to HMT, and the voids among the alumina grains. The porosity contributed by each of pore types was estimated by comparing the deconvoluted peak area ratios to the whole porosity; the calculated porosities were 30.2 and $34.1 \%$ at the 4 and $11 \mu \mathrm{m}$ peaks, respectively.

Figures 6(a) and 6(b) show SEM images of the porous alumina surface and cross section, respectively, prepared with the filter paper during the heat-treatment, while Figs. 6(c) and 6(d) show the surface and cross section of that prepared with the dense plastic sheet instead of the filter paper. Figures 6(e) and 6(f) show higher magnification images of that with the filter paper. As shown in Fig. 6(a), the surface was relatively dense without cracks and coarse pores. The cross-section in Fig. 6(b) also shows the denser surface layer above the porous body that is composed of coarse alumina grains. On the other hand, the surface that was covered with a dense plastic sheet during the heat-treatment appeared to be porous due to the spherical pores formed by the blowing gas. The cross section also shows that there were spherical pores near the surface. The filter paper thus played an important role in the formation of the denser surface layer.

Figure 6(e) shows a typical spherical pore observed in the 
porous body in Fig. 6(b); it has a diameter of $64 \mu \mathrm{m}$, and is surrounded by coarse alumina grains. The pore contained a window-like small pore (marked with a white arrow; pore diameter of $17 \mu \mathrm{m}$ ) in the inside wall, presumably resulting from contact points among the blowing bubbles during foaming. Figure 6(f) shows a higher magnification image of the coarse alumina grains observed in the denser surface layer of Fig. $6(\mathrm{~b})$. The coarse alumina grains were bonded via necking (marked with black arrows) due to sintering of the fine alumina particles, and formed voids of several micrometers among them. Thus, the pores of the porous alumina were roughly classified into two types; (1) voids among the coarse alumina grains, which correspond to the peak of $4 \mu \mathrm{m}$ shown in Fig. 5, and (2) spherical pores produced by direct foaming, which correspond to the peak of $11 \mu \mathrm{m}$. Since the denser surface layer contained almost solely the former type of pores, its porosity was considered to be equivalent to that calculated from the peak of $4 \mu \mathrm{m}$ shown in Fig. 5 , $30.2 \%$. Considering that the porosity of the whole specimen was $64.3 \%$, the surface layer is more than twice as dense as the porous body.

The thickness of the denser surface layer was determined from changes in the occupancy by spherical pores above a $20 \mu \mathrm{m}$ depth. The occupancy $[D(\%)]$ was measured using the intercept
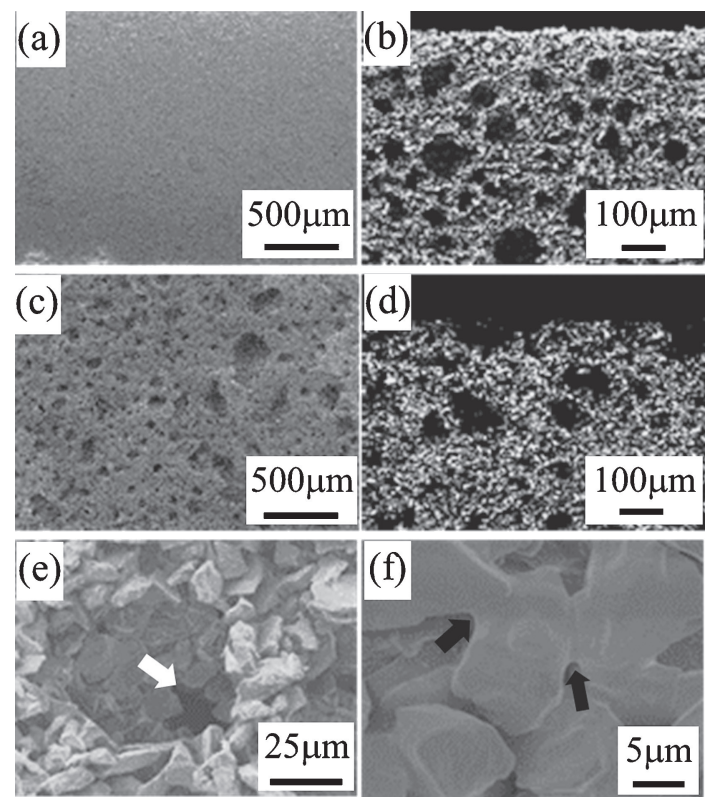

Fig. 6. SEM images of the porous sintered alumina. (a) surface and (b) cross-sectional image of the specimen prepared with the filter paper. (c) surface and (d) cross-sectional image of that with plastic sheet. (e and f) higher magnification images of that with the filter paper. line in the cross-sectional images [Fig. 6(b)]. When the straight line passed through spherical pores which had a diameter above $20 \mu \mathrm{m}$, the segment length of the pore was recorded. The percentage of the recorded length over the total, $D(\%)$, was plotted as a function of depth from the surface, as shown in Fig. 7. The value of $D$ was about $2 \%$ at a depth of $20 \mu \mathrm{m}$ and remained constant $40 \mu \mathrm{m}$, then drastically increased at $60 \mu \mathrm{m}$ or deeper, reaching a saturation value of $36 \%$ at $140 \mu \mathrm{m}$. Therefore, the thickness of the denser surface layer was estimated to be $40-60 \mu \mathrm{m}$, which agreed relatively well with that of the similar denser surface layer observed in RB-SiC, which was approximately $50 \mu \mathrm{m} .{ }^{12)}$

Figure 8 shows a schematic illustration of the formation mechanism of the porous structure and the denser surface layer by the direct-foaming process. Two steps were observed in the specimen by heat-treatment up to $150^{\circ} \mathrm{C}$. The first step was densification by melting of the novolac resin from 80 to $120^{\circ} \mathrm{C}$. In this temperature range, the alumina particles were rearranged with the molten novolac resin to decrease the surface area of the specimen for densification. The second step was the formation of the porous body, as well as the surface layer that was more than twice as dense and $40-60 \mu \mathrm{m}$ in thickness. Around $150^{\circ} \mathrm{C}$, HMT decomposed into the blowing gas in the specimen. The blowing gas produced spherical pores, which increased the volume of specimens, and cured the molten novolac resin leading to stabilization of the spherical pores. While the blowing gas produced a porous structure inside, it evolved outwards near the surface through the filter paper placed on it, resulting in the formation of a denser surface layer.

The bending strengths with and without (for comparison) the denser surface layer were $4.2 \pm 0.3$ and $3.2 \pm 0.1 \mathrm{MPa}$, respectively, and the porosities were 66.3 and $66.8 \%$. Since the porosities were almost equivalent to one another, the observed strength improvement of $31 \%$, was mostly due to the denser surface layer. However, the value of $4.2 \mathrm{MPa}$ was low compared to values

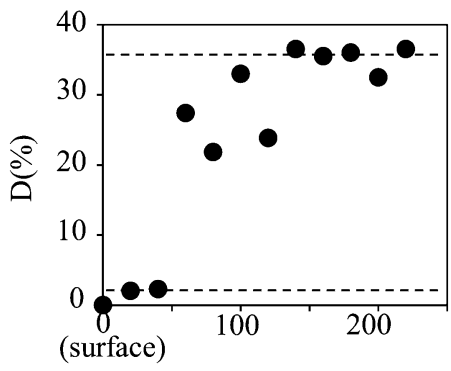

Depth from surface $(\mu \mathrm{m})$

Fig. 7. Distribution of spherical pores with $20 \mu \mathrm{m}$ diameter or larger in denser surface layer.

\section{Initial state (as prepared) \\ 1. First step (densification) \\ 2. Second step \\ (formation of porous} structure and denser surface)

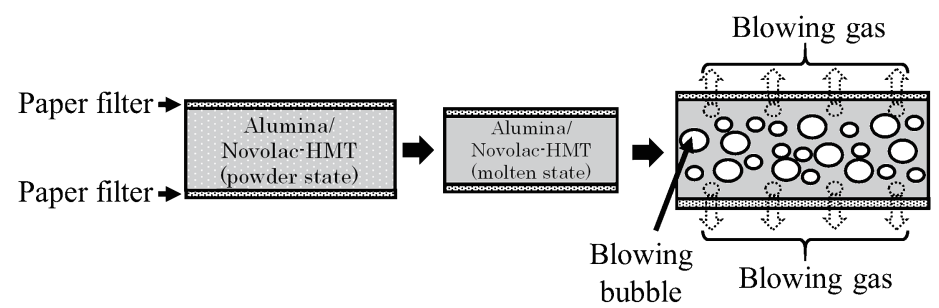

Fig. 8. Schematic illustration of the formation mechanism of the porous structure with a denser surface by the direct foaming. 
reported for porous alumina of fine powder with equivalent porosity. ${ }^{7)}$ Thus this low value is presumably due to the lower sinterability of the coarse powder employed in this study. Several researchers discussed ideal mixing of coarse and fine alumina powders, and reported that the fine powder content at optimum packing was around $20-30 \mathrm{wt} . \%,{ }^{25)-27)}$ much higher than the $2 \mathrm{wt} . \%$ of fine alumina used in this study. In future work, we will examine possible improvements in the mechanical strength by adjusting the ratio of fine to coarse alumina.

\section{Conclusion}

In this study, porous alumina with a denser surface layer was fabricated via direct foaming of alumina/novolac-HMT composites. We demonstrated that a drastic thermal change took place twice in the composite before the porous structure and the denser surface layer were obtained. Firstly, the composite densified due to shrinkage by melting of the novolac resin. Secondly, the densified composite expanded via thermal decomposition of HMT into the blowing gas. While the blowing gas produced the porous structure inside, the denser surface layer was created by evolving blowing gas near the surface outward through the filter paper. The denser surface layer and the porous structure were maintained without cracking after debinding and sintering at $1600^{\circ} \mathrm{C}$. The sintered alumina had two types of pores; the voids among the alumina grains and the spherical pores formed by the blowing gas. The surface layer's density was more than twice that of the porous body, and its thickness was estimated to be 40 $60 \mu \mathrm{m}$. The mechanical strength was improved by $31 \%$ due to formation of the denser surface layer.

\section{Reference}

1) P. J. Gellings and H. J. M. Bouwmeester, Catal. Today, 58, 1$53(2000)$.

2) J. Liu, Y. Li, Y. Li, S. Sang and S. Li, Ceram. Int., 42, 82218228 (2016).

3) T. F. Baumann, A. E. Gash, S. C. Chinn, A. M. Sawvel, R. S. Maxwell and J. H. Satcher, Chem. Mater., 17, 395-401 (2005).

4) P. Colombo, Philos. Trans. R. Soc. London A: Math., Phys. Eng. Sci., 364, 109-124 (2006).

5) M. Fukushima, Y.-i. Yoshizawa and T. Ohji, Adv. Eng. Mater., 16, 607-620 (2014).
6) P. Colombo, E. Bernardo and L. Biasetto, J. Am. Ceram. Soc., 87, 152-154 (2004).

7) V. Sciamanna, B. Nait-Ali and M. Gonon, Ceram. Int., 41, 2599-2606 (2015).

8) T. Ohji and M. Fukushima, Int. Mater. Rev., 57, 115-131 (2012).

9) A. R. Studart, U. T. Gonzenbach, E. Tervoort and L. J. Gauckler, J. Am. Ceram. Soc., 89, 1771-1789 (2006).

10) S. Barg, C. Soltmann, M. Andrade, D. Koch and G. Grathwohl, J. Am. Ceram. Soc., 91, 2823-2829 (2008).

11) M. Fukushima and P. Colombo, J. Eur. Ceram. Soc., 32, 503510 (2012)

12) A. Shimamura, M. Fukushima, M. Hotta, T. Ohji and N. Kondo, J. Ceram. Soc. Japan, 123, 1106-1108 (2015).

13) J. Qian, Z. Jin and J. Wang, Mater. Sci. Eng., A, 368, 71-79 (2004).

14) L. Shi, H. Zhao, Y. Yan, Z. Li and C. Tang, Powder Technol., 169, 71-76 (2006).

15) A. Shimamura, M. Fukushima, M. Hotta, T. Ohji and N. Kondo, J. Am. Ceram. Soc., 99, 440-444 (2016).

16) I. Iliev, H. Yordanova, P. Petrenko and P. Novakov, J. Chem. Technol. Metall., 41, 29-34 (2006).

17) C. Zhang, W. K. Binienda, L. Zeng, X. Ye and S. Chen, Thermochim. Acta, 523, 63-69 (2011).

18) J. Wan, S. Wang, C. Li, D. Zhou, J. Chen, Z. Liu, L. Yu, H. Fan and B.-G. Li, Thermochim. Acta, 530, 32-41 (2012).

19) E. S. De Medeiros, J. A. M. Agnelli, K. Joseph, L. H. De Carvalho and L. H. C. Mattoso, J. Appl. Polym. Sci., 90, 1678$1682(2003)$.

20) S. A. Sojka, R. A. Wolfe and G. D. Guenther, Macromolecules, 14, 1539-1543 (1981).

21) G. R. Hatfield and G. E. Maciel, Macromolecules, 20, 608-615 (1987).

22) R. C. Korošec, L. Ž. Mežnar and P. Bukovec, J. Therm. Anal. Calorim., 95, 235-240 (2009).

23) T. T. Jones, J. Appl. Chem., 2, 134-149 (1952).

24) K. Ishizaki, S. Komarneni and M. Nanko, "Porous materials: process technology and applications", Ed. by Kluwer Academic Publishers, Dordrecht, Boston (1998).

25) S. Kwon and G. L. Messing, J. Mater. Sci., 33, 913-921 (1998).

26) S. Taruta, K. Kitajima, B. Takusagawa, Y. Takagai, K. Okada and N. Ōtsuka, J. Mater. Sci. Lett., 12, 424-426 (1993).

27) J. C. Goldsby, Ceram. Int., 27, 701-703 (2001). 